\title{
Recent advances in the stability assessment of natural and engineered rock slopes
}

\author{
*Deepak P Adhikary, Marc Elmouttie, Vincent Lemiale, and Brett Poulsen \\ Commonwealth Scientific and Industrial Research Organisation (CSIRO), Australia \\ (*Email: Deepak.adhikary@csiro.au)
}

\begin{abstract}
Science's understanding of the failure mechanisms of large natural and engineered slopes has been improved considerably over the past 15 years. Significant improvements have been realized in innovative methods of data acquisition through field measurement and monitoring, as well as numerical modelling techniques. However, inadequate understanding of complex geology and landslide processes means that any interpretation of landslide data remains mostly subjective. This causes major uncertainty in landslide risk assessment.

Over the past decade, Australia's Commonwealth Scientific and Industrial Research Organisation (CSIRO; http://www.csiro.au/) has developed novel techniques to facilitate efficient assessment of rock slope stability. These include Sirovision ${ }^{T M}$, Siromodel, and three CSIRO numerical codes: CSIRO-SPH, CSIRO-DEM and CSIRO-COSFLOW.

Sirovision $^{T M}$ is a geological/geotechnical mapping and analysis system that generates accurate, scaled 3D images of rock faces from stereo photographs of exposed rock surfaces, allowing for rapid rock mass structural mapping. Siromodel is a polyhedral modelling system that reads the Sirovision ${ }^{T M}$ data, generates discrete fracture networks (DFN) and performs polyhedral (rock block) modelling and a first-pass stability analysis.

CSIRO-SPH, CSIRO-DEM and CSIRO-COSFLOW are all used for detailed stress-deformation analysis of rock slopes; however, each code has its own problem-specific advantage. CSIRO-SPH is suited for large deformation problems, and can simulate large scale fluid flow problems, such as modelling a dam breakage. CSIRO-DEM is suited for rock breakage process analysis, and assessment of the runout distance of failure debris. CSIRO-COSFLOW is designed specifically for efficient, accurate stress-deformation analysis of stability of structures on bedded sedimentary rocks, where failures along the preexisting bedding planes and through the intact rock layers occur simultaneously.
\end{abstract}

Keywords: Rock slope stability, Landslide Assessment, Discrete Fracture Network, Smooth particle hydrodynamics, Numerical modelling

Paper Received: 13 May 2015

Paper Accepted: 18 December 2015

\section{INTRODUCTION}

Landslides vary in size; they can be as small as the movement of a single block of rock in a minor rockfall or as big as thousands or millions of cubic metres of earth and debris that slide and roll down hills. Although most common in mountainous areas, landslides can occur in any environment in which conditions can generate forces capable of inducing rock

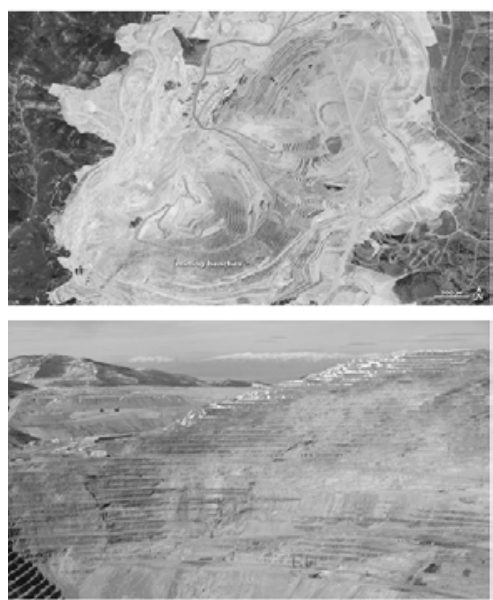

or soil failure. A poor understanding of the stability of natural and engineered slopes can have devastating effects. Both landslides and failures of engineered slopes cause hundreds of millions of dollars' worth of damage, and every year on average, claim more than a thousand lives around the world. This is illustrated by the following three examples (Figs. 1, 2 and 3).

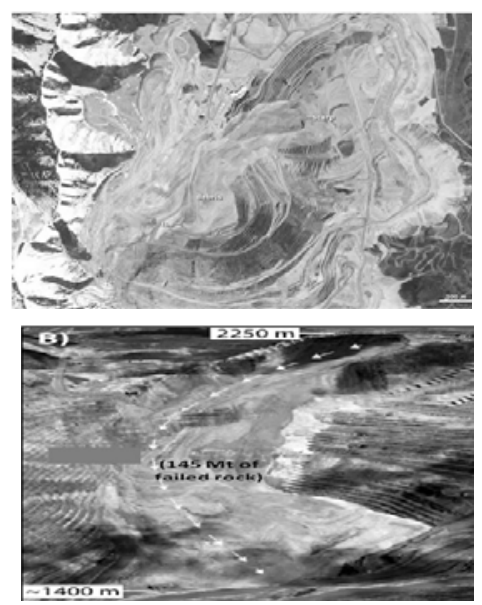

Fig. 1: Bingham Canyon Mine: satellite images before July 20, 2011 (top left) and after May 2, 2013 (top right), Source: http://en.wikipedia.org/wiki/Bingham_Canyon_Mine; (bottom left) and (bottom right): images before and after failure, courtesy of J. Read. 

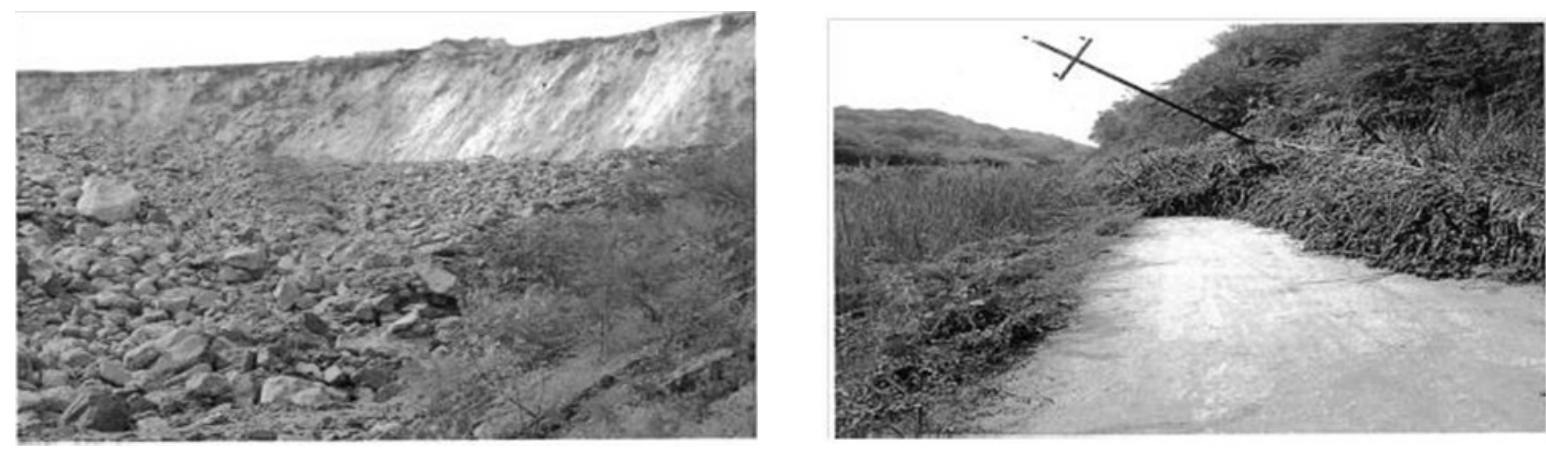

Fig. 2: Overburden dump failure in an Indian mine in 2009: images of dump site after failure (left) and effect on a local road (right), courtesy of DN Sharma of Singareni Collieries Company Limited (SCCL).
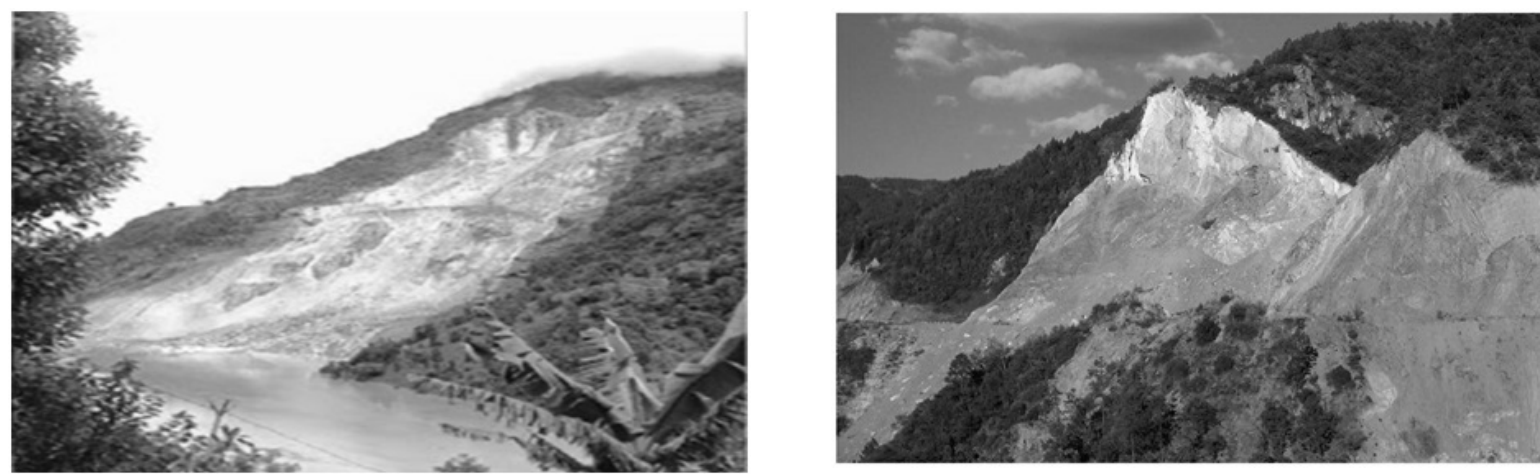

Fig. 3: Landslides along mountain roads in Nepal (Left) and China (Right). Left: Photo source: http:// www.disaster-report.com/2014/08/massive-landslide-near-barabise-blocks-bhotekoshi-river.html. Right: Photo reproduced with permission from Sidle and Ziegler (2012).

(i) An extremely large landslide occurred in the Bingham Canyon copper mine in Utah, United States, in April 2013 (Fig. 1). According to news reports, the slope deformation was detected several weeks before the landslide, and was being monitored intensively. An increasing rate of strain in the hours before failure indicated that a collapse was imminent, and helped release advance warning, allowing evacuation of all people from the pit. This is a real geotechnical monitoring success story. Although the landslide caused considerable damage to the mine, no casualties resulted. The pit failure involved about 140 million cubic metres of waste rocks, which moved at an average speed of around $110 \mathrm{~km} / \mathrm{hr}$. Equipment damage, halted production and remediation resulted in a loss of hundreds of millions of dollars.

(ii) An external overburden (OB) dump servicing an Indian mine failed in 2009. The OB dump was at the designed maximum height of $90 \mathrm{~m}$ and contained approximately 34 million cubic metres of waste material. After the failure, the flow of material travelled about $70 \mathrm{~m}$ from the original toe location, overwhelming local electricity services and drainage works, and encroaching on a road (Fig. 2).

(iii) Rapid expansion of road networks in the hilly regions has significantly increased the occurrence of landslides throughout the world. In many instances the main reason of slope failures remains the anthropogenic activities (e.g. constructions/ expansions of roads and highways) carried out without proper geotechnical investigation and consideration disrupting the fragile balance of natural slopes. Fig. 3 shows large scale slope failures along mountain roads in Nepal and China. The landslide in the Sindhupalchowk District of Nepal, is $120 \mathrm{~km}$ north-east of Kathmandu, killed many people. The Chinese landslide, which occurred along a newly constructed mountain road near Weixi (Yunnan Province), killed six people and transported most of the sediment directly into a tributary of the Mekong River.

Our understanding of large landslide mechanics has advanced greatly over the past two decades. For example, basic research in engineering and the physical sciences, combined with new technologies and better computational capabilities, has improved our understanding of the causes, triggers and mechanics of landslides. New measurement and monitoring techniques, such as the borehole televiewer, photogrammetry, LiDAR remote sensing and high-resolution InSAR monitoring, have generated extensive amounts of data. However, due to inadequate focus in understanding of complex geology and landslide processes, the interpretation of such data still remains mostly subjective. Researchers and engineers still therefore 
face major challenges and uncertainties when characterising and modelling the complexities of landslide processes.

\section{ROCK MASS STRENGTH}

Determining appropriate shear strength parameters is critical during slope design, because small changes in shear strength may result in significant changes to the safe slope angle. In light of the behaviour of the rock mass that makes up the rock slope, careful evaluation of strength parameters is a necessity. Sjöberg (1996) demonstrated that for a 500-m-high slope cut into a homogeneous, isotropic rock mass, an increase in cohesion of only $0.3 \mathrm{MPa}$ could raise the stable slope angle from $40^{\circ}$ to $50^{\circ}$ (assuming a rock mass friction angle of $30^{\circ}$ ). This suggests that small changes in the strength parameters may correspond to relatively large changes in slope geometry, which can be of great economic significance in road construction or mining projects. Nilsen (1979) demonstrated that an increase of intact rock portion (rock bridge) from $0 \%$ to $10 \%$ along the failure path could yield a five-fold increase in the factor of safety from 0.3 to 1.7 .

Practicing engineers often estimate rock mass strength parameters using either back analyses, or empirical methods based on rock mass rating (RMR) or the geological strength index (GSI). The RMR/GSI technique estimates the reduction in rock mass strength due to adverse geological conditions. However, such an approach yields largely isotropic strength parameters, and is hence often unable to capture the inherent anisotropy in rock mass strength. It is also unclear whether the strength parameters derived using either back analyses or empirical methods are free of scale effects.

\section{CSIRO RESEARCH FOCUS}

Over the past decade, Australia's Commonwealth Scientific and Industrial Research Organisation (CSIRO) has developed novel techniques to facilitate efficient assessment of rock slope stability. These include:

- $\quad$ Sirovision $^{T M}$ - for rock mass structural mapping

- Siromodel - for discrete fracture network (DFN) generation, polyhedral (rock block) modelling and kinematic analysis

- CSIRO-SPH, CSIRO-DEM and CSIRO-COSFLOW - for large-scale rock mass stress deformation analysis.

CSIRO has also recently published two books Guidelines for Open Pit Slope Designs and Guidelines for Evaluating Water in Slope Stability - which address some key issues in the design process of large open pits. These books cover aspects of slope design such as data collection, development of geological, hydrogeological and geotechnical models, and slope stability assessment and monitoring. See Read and Stacey (2009) for a detailed description of each of the components involved in the slope design process.

\section{Sirovision $^{T M}$}

Sirovision $^{T M}$ is a structural mapping and analysis system that has been commercialised with Data-Mine. The system turns digital photographs into high-precision 3D images of the rock mass surface. The 3D images are then used to map the distribution of geological features, such as joints, bedding and faults daylighting on the surface of the rock mass. Large areas can be mapped quickly and safely, because personnel are not required to approach hazardous slopes. Sirovision ${ }^{T M}$ also provides advanced tools for the kinematic analysis of daylighting structures. Fig. 4 shows a section of a 3D image with structures mapped using Sirovision ${ }^{T M}$.

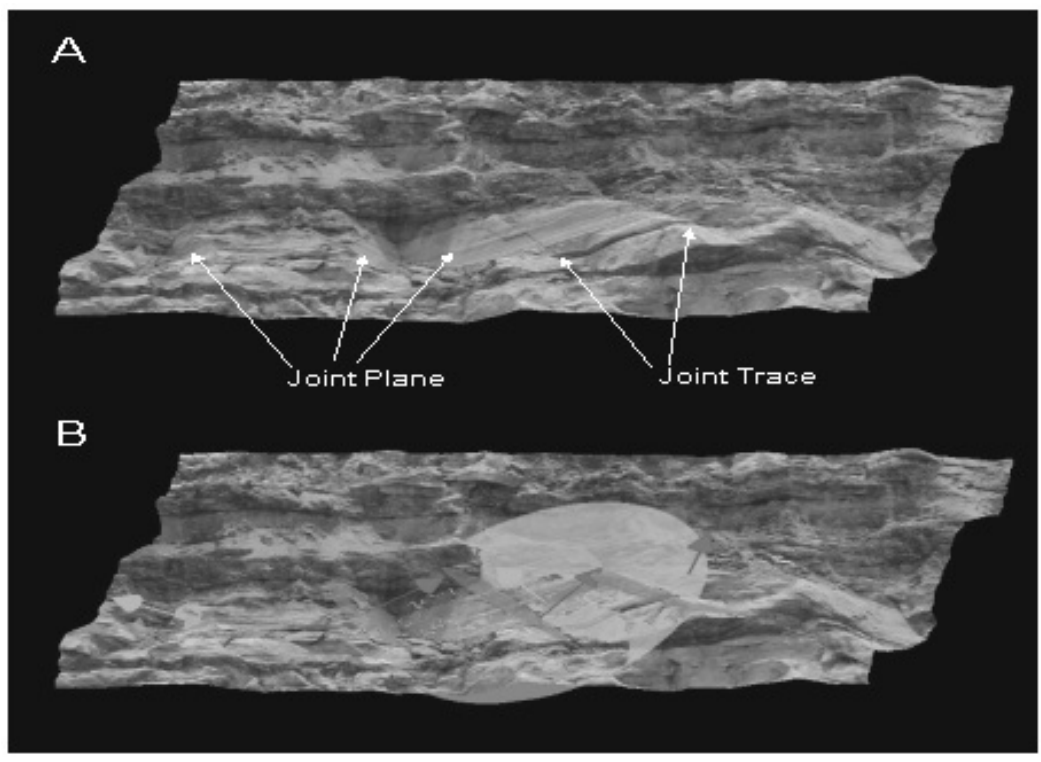

Fig. 4: Structure mapping in Sirovision ${ }^{T M}$ : (A) 3D image with several structures highlighted, (B) the same image with joints fitted. Source: Elmouttie et al. (2010). 

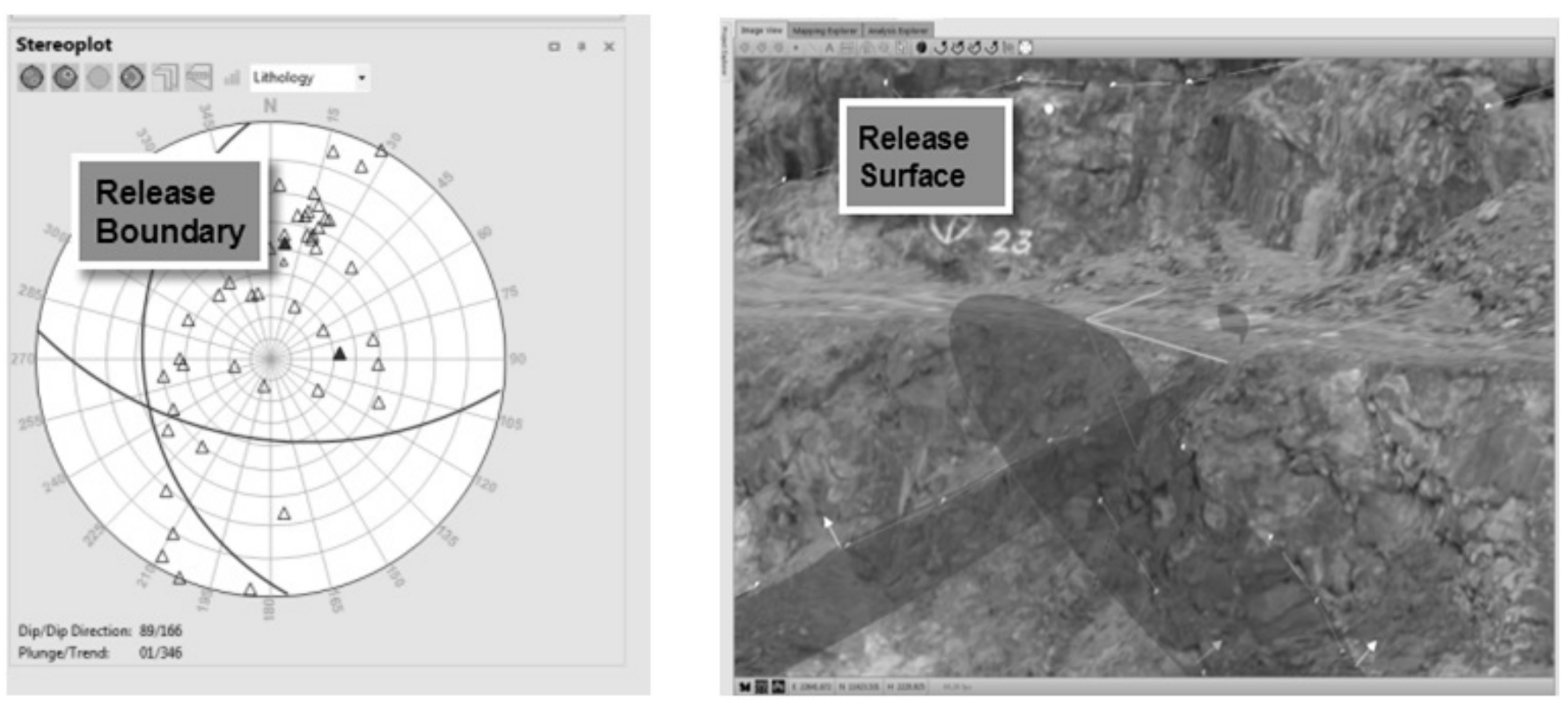

Fig. 5: Visualisation of the results of a Sirovision ${ }^{T M}$ stability analysis using either stereonet or wedge visualisation. Source: CAE Sirovision ${ }^{T M}$ User Manual (2013).

Sirovision ${ }^{T M}$ incorporates a sophisticated structure mapping and analysis functionality. The interface allows the user to visualise 3D mosaics, and digitally map and analyse structures (Fig. 5). The analysis module provides facilities to:

- plot discontinuity distributions using equal angle, equal area projections of dips or normals

- plot discontinuity distributions using rose diagrams with the plot length or area proportional to the number of discontinuities

- analyse distributions using contouring or statistical clustering

- calculate normal set spacing for sets of discontinuities, and visualise the discontinuities used for set spacing calculations

- visualise discontinuities and the 3D images or mine layout in which they exist

- undertake a wedge-based stability analysis based on pairs of structures and user-defined intersection criteria.

\section{Siromodel}

CSIRO developed the Siromodel software application for the Large Open Pit Mine Slope Stability Project. The software uses DFN to provide a realistic simulation of rock mass heterogeneity, and polyhedral modelling techniques to model sections of an open pit excavation for slope stability analyses. Statistics on each polyhedron or block predicted by the software can be generated, including limit equilibrium stability assessment, and the blocks can be viewed individually or as an ensemble.

\section{Polyhedral modelling}

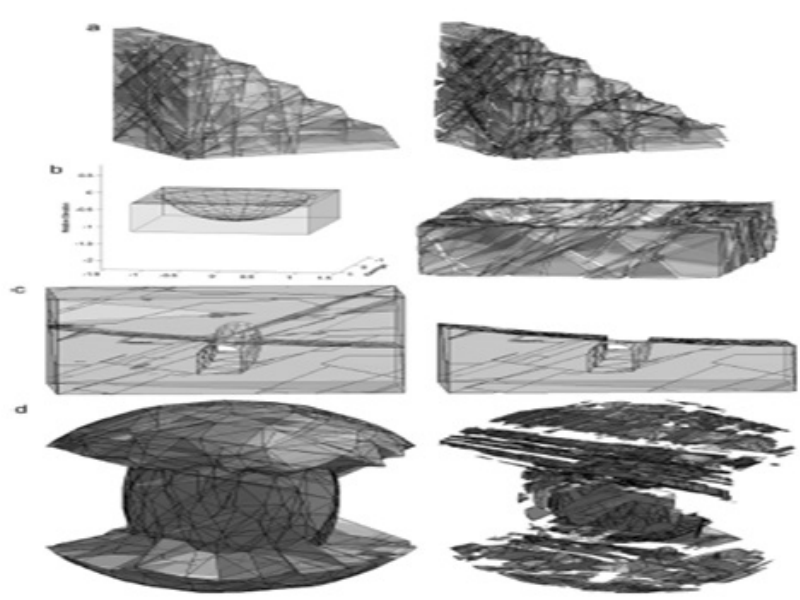

Fig. 6: Examples of polyhedral models: (a) open pit benches, (b) bowl-shaped excavation, (c) underground excavation and (d) pillar. Source: EImouttie et al. (2010).

Identification of the polyhedra or rock blocks present in a rock mass is an important tool in the application of block theory and numerical studies of rock mass stability. Polyhedral modelling does not provide the same level of physics sophistication as numerical stress-strain modelling. However, it is extremely useful for several reasons. It is:

- more advanced than traditional analysis

- compatible with fast, first-pass analyses

- compatible with statistical sampling schemes such as Monte Carlo 
- able to provide estimates of in-situ block size distribution, slope stability and rock mass fragmentation when coupled with accurate structural representations.

Used in isolation from numerical techniques, polyhedral modelling will provide an estimate of the $3 \mathrm{D}$ fragmentation of

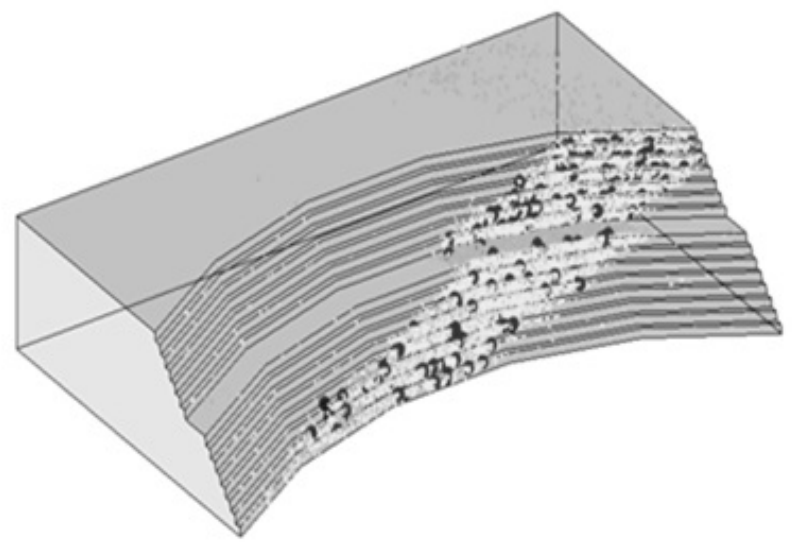

a rock mass, but will not account for stress-induced fracture propagation. Numerous polyhedral modelers have been described in the literature and used to estimate block size distribution (e.g. Menéndez-Díaz et al. 2009). Examples of polyhedral models are shown in Fig. 6.

\section{Monte Carlo simulation}

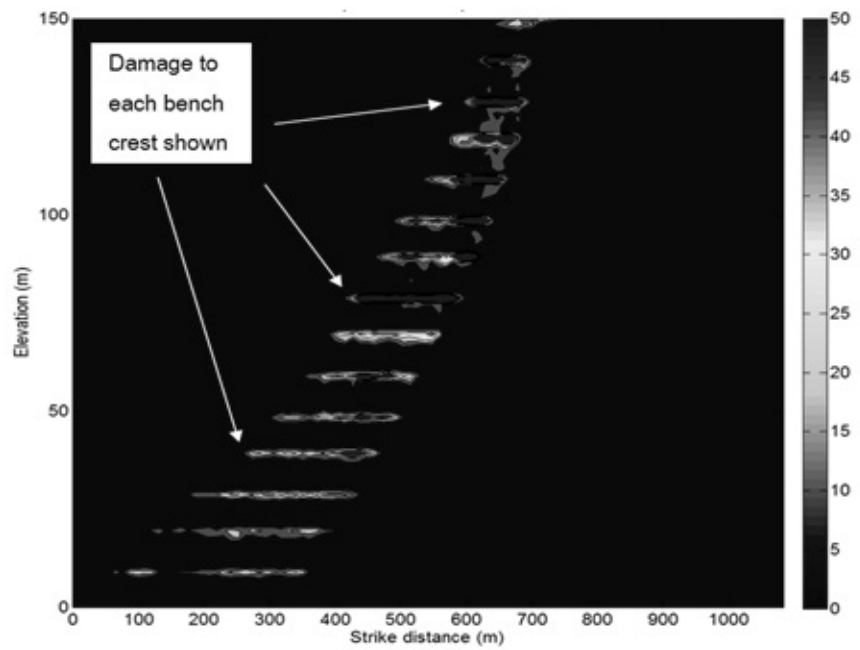

Fig. 7: Example of a discrete fracture network (DFN) realisation and resulting analyses for a section of an open pit mine: Left - aggregated results of stability analysis for 100 realisations; Right - hazard map generated from 100 realisations. Vertical axis exaggerated for clarity. Source: Elmouttie et al. (2010).

Any particular DFN realisation represents one of an infinite (but equiprobable) number that could have been generated with large variances in properties being possible. Therefore, reliance on one or even a few realisations is statistically insignificant, because analyses based on small numbers will be particularly sensitive to statistical outliers in the fracture geometry and properties. By repeatedly sampling from the probability distributions of the fracture parameters, generating a DFN realisation and finally performing a geotechnical analysis, one can capture the stochastic variability of the rock mass using multiple deterministic analyses. In turn, this can guide the practitioner in determining realistic outlier scenarios requiring more detailed, sophisticated or time-consuming analyses.

In practice, a structural model incorporates the deterministic structures that have been explicitly measured (e.g. larger structures such as faults or large fractures that have been mapped on an exposure), and the stochastic or inferred structures that have been realised via a DFN. It is particularly important to include these large existing structures deterministically in a DFN, because stochastic generation of large fractures can severely alter the geometries, as well as subsequent hydrological, stability and other analyses. The properties of stochastic structures in the DFN are represented as random variables. Therefore, statistical methods must be used to generate simulated fracture networks. Siromodel allows the user to perform Monte Carlo simulations and generate multiple
DFN realisations - each with an associated polyhedral model - and therefore, accumulate statistics on hazard locations and likelihood (Fig. 7).

\section{CSIRO - Equivalent Rock Mass Modelling Approach}

Recent advances in numerical modelling techniques and the characterisation of complex slope deformation and failure have demonstrated the potential for incorporating realistic geological features into the geotechnical behaviour models used for stability analyses of small to medium-scale slopes. In such an approach, the geotechnical models will have realistic representations of discontinuities. However, it is infeasible to incorporate all the existing geological features explicitly for the analysis of large-scale slopes constructed in a heavily jointed rock mass. Thus, the current practice of slope design uses empirical methods (e.g. RMR, GSI) to indirectly estimate rock mass parameters that will be used in stability analysis, such as strength and deformation modulus.

With the advent of powerful computers and advanced numerical tools, it is now possible to conduct numerical compression and extension tests on larger rock mass blocks for estimating strength and deformation parameters. As opposed to laboratory tests, in which rock specimen size is limited to centimetres, this approach can numerically simulate large specimens with sizes in metres. This allows for the explicit inclusion of the geological features into the numerical specimen, thus better representing the behaviour of the real rock mass. 
CSIRO uses this method to estimate geotechnical domain-wise equivalent rock mass strength deformation parameters. In this approach, the rock mass constitutive properties and behaviour will be governed by the integrated behaviour of the intact rock, fractures and rock bridges. This approach is very different from treating the rock mass as an equivalent continuum with, say, a uniform Mohr-Coulomb criterion using empirical approaches.

A jointed rock mass may exhibit both heterogeneity and anisotropy. However, the rock mass strength models obtained from empirical methods are essentially isotropic, and thus may not adequately define the constitutive behaviour of the rock mass. The equivalent rock mass (ERM) modelling approach overcomes this limitation by performing numerical compression tests on large-scale rock mass specimens. The numerical simulation allows one to investigate (a) the so-called size (scale) effect on load deformation characteristics; (b) strength anisotropy; and (c) strength heterogeneity. This approach extensively uses two models: the bonded particle model, to simulate the intact rock behaviour; and DFN simulations, to construct a 3D representation of defect distribution (Fig. 8). The development of an ERM model is therefore a three-step process:

1. A particle assembly is created using a discrete element method (DEM) code (e.g. PFC3D), representing the intact rock within the considered geotechnical domain.

2. A fracture network representative of the joint fabric is generated using Siromodel and imported into the particle assembly to create a large synthetic rock mass sample.

3. The sample is submitted to a variety of loadings to predict the rock mass behaviour.

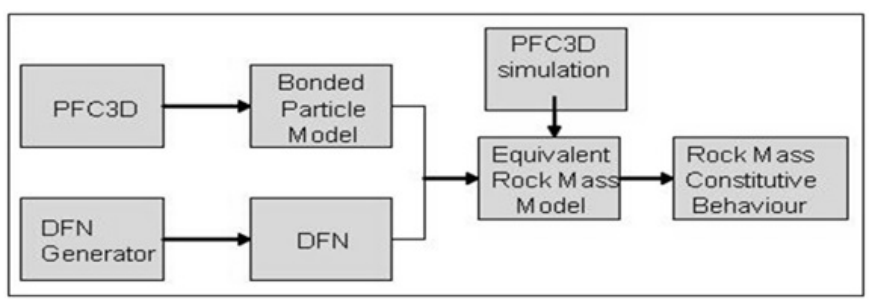

Fig. 8: Flow chart of development of rock mass constitutive behaviour models.

\section{DFN realisation}

The example given in Fig. 9 is of DFN modelling conducted for a mine site in Australia using mine site data such as joint dip angle, joint dip direction, scanline/core-end coordinates, scanline censor window and cut-off size, and joint trace length. All together, there were nine of mapped joint sets and associated data (Table 1, Fig. 9) shows the match in the joint input data and output generated (left), while on the right it shows the DFN realisation of the rock mass using the nine types of mapped joint set data.
Table 1: Joint in put data and DFN realizeation outputs.

\begin{tabular}{|c|r|r|r|r|r|r|}
\hline \multirow{2}{*}{$\begin{array}{c}\text { Joint } \\
\text { set }\end{array}$} & \multirow{2}{*}{$\begin{array}{c}\text { Dip } \\
\text { angle }\end{array}$} & \multirow{2}{*}{$\begin{array}{c}\text { Dip } \\
\text { direction }\end{array}$} & \multicolumn{2}{|c|}{ Spacing } & \multicolumn{2}{|c|}{ Length } \\
\cline { 5 - 7 } & & Input & $\begin{array}{c}\text { DFN } \\
\text { realisation }\end{array}$ & Input & $\begin{array}{c}\text { DFN } \\
\text { realisation }\end{array}$ \\
\hline 1 & 75.4 & 265.3 & 4.14 & 4.15 & 12.6 & 12.46 \\
\hline 2 & 76.9 & 83.8 & 5.61 & 5.59 & 14.7 & 14.51 \\
\hline 3 & 43.7 & 259.1 & 5.97 & 5.85 & 10.6 & 10.39 \\
\hline 4 & 1.5 & 165.8 & 7.00 & 6.99 & 34 & 34.02 \\
\hline 5 & 37.8 & 81.4 & 14.05 & 13.89 & 10.3 & 10.22 \\
\hline 6 & 83.4 & 203.1 & 2.26 & 2.26 & 2.37 & 2.43 \\
\hline 17 & 85.5 & 142.2 & 22.65 & 22.73 & 3.73 & 3.68 \\
\hline 18 & 38.7 & 130.1 & 14.25 & 14.29 & 5.81 & 5.73 \\
\hline 25 & 86.8 & 328.4 & 18.17 & 18.18 & 3.52 & 3.48 \\
\hline
\end{tabular}

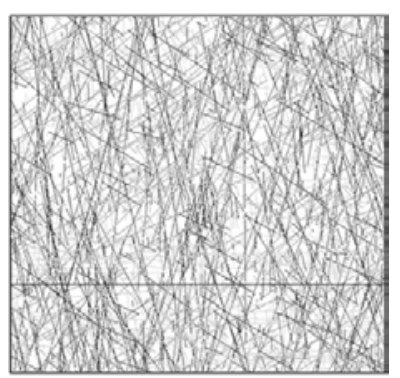

Fig. 9: Discrete fracture network realisation of a rock mass using nine types of mapped joint set data.

\section{Large scale rock mass strength estimation}

To represent actual lithology correctly, the intact rock matrix developed in PFC3D was assigned with 57\% Mafic Volcanics, 25\% Mafic Intrusive and 18\% Basalt. The rock units were randomly distributed in the model, as we lacked the data needed to define their spatial distribution within the geotechnical domain.

Lumping different rock units contained within one geotechnical domain into a model with average properties is not ideal; effort must be made to represent each lithology individually in any stability analysis. However, in the cases of complex geology, subdividing the domains can require exhaustive rock type mapping and generation of an unreasonable number of geotechnical units for subsequent slope stability analyses. Such cases may warrant an alternative approach to developing an ERM model that reflects the different rock types within the domain. Creating a randomly distributed mixture of the rock types seems to be a straightforward way to overcome the problem, and is a first-pass simplification of reality.

To study the anisotropy and variability that can result from a DFN, or the heterogeneity in the rock mass, we picked 24-m cubes from three locations. The specimens were numerically loaded in three directions to determine the strength deformation characteristics, and to see if there was any anisotropy within the domain. The uniaxial compressive strength (UCS) tests carried out in the N-S direction are presented in Fig. 10 (Top). 

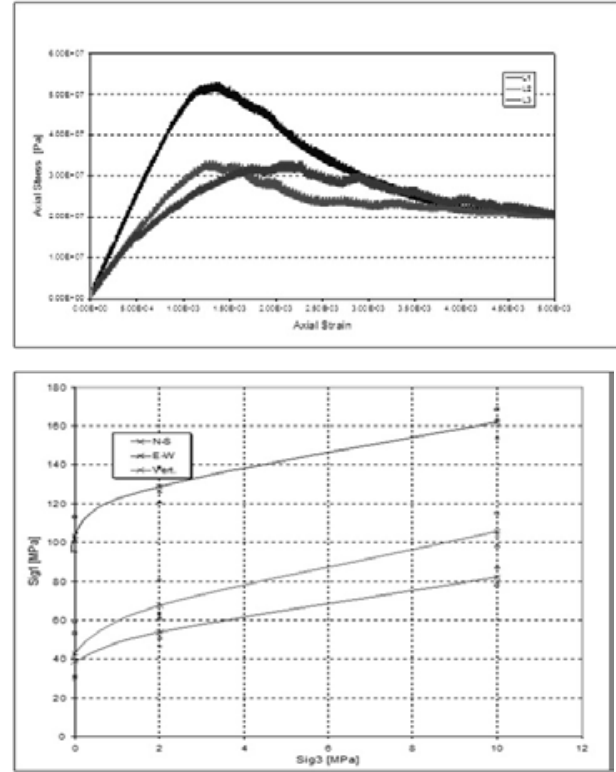

Fig. 10: Uniaxial compression tests of 24-m cube taken from the three locations (Top). Strength envelopes derived from synthetic rock mass modelling (Bottom).

The residual strength of the rock mass is predicted to be around $20 \mathrm{Mpa}$, irrespective of the location of the 24-m cube within the DFN (see the stress strain curve in Fig. 10). The elastic modulus seems to rise with the increase in the confining stress. The elastic moduli in the E-W loading direction are estimated to be much higher than those in other loading directions.

Fig.10 (Bottom) shows the strength envelopes obtained from the triaxial compression tests simulated on the same three 24-m cubes. The tests were conducted at confining pressures of $200 \mathrm{kPa}, 2 \mathrm{MPa}$ and $10 \mathrm{MPa}$. Loads were applied in three directions (vertical, horizontal N-S, and horizontal E-W) in succession to study the anisotropy. Apart from heterogeneity, there is a clear indication of strong anisotropy in strength. The strength envelopes indicate that the rock mass may exhibit almost double strength when loaded in the E-W direction compared with the N-S or vertical directions. The strength in the vertical direction is about $20-30 \%$ higher than in the N-S direction.

The DFN can also be used to study the effect of specimen size on strength clearly reproducing a trend of strength reduction with increasing specimen size, commonly referred to as the scale effect.

\section{CSIRO-SPH - Smoothed-Particle Hydrodynamics}

Smoothed-particle hydrodynamics (SPH) is a computational method used mainly to simulate fluid flows. It was developed by Gingold and Monaghan (1977) and Lucy (1977), initially for astrophysical problems, but is used in many fields of research, including astrophysics, ballistics, volcanology and oceanography. SPH is a mesh-free Lagrangian method, in which the material points or particles move with the fluid. The resolution of the method can easily be adjusted with respect to variables such as density.

During the past two decades, SPH has been applied to various areas of computational solid mechanics. These include fragmentation in solids (Randles and Libersky 1996), impact of elasto-plastic materials (Cleary 2010) and brittle fracture in rocks (Das and Cleary, 2010). Unlike many of available SPH codes, CSIRO-SPH fully considers plasticity in its formulation to capture the plastic behaviour of materials and predict the initiation of a macroscopic instability in a slope.

Conceptually, SPH is a continuum method that can be used to solve partial differential equations for a deforming volume of material that is discretised using a set of Lagrangian particles. SPH formulation is fully described in Cleary (2010) and the references cited therein. In SPH, the governing equations must be supplemented with appropriate constitutive laws that are suited to the medium and circumstances under consideration.

Fig. 11 (Left) is a schematic of pre and post-failure profiles of two OB dumps in a mine in India, while Fig. 11 (Right) presents the CSIRO-SPH simulation of the failure of dump No 1, showing the equivalent plastic strain within the dump computed at three different times during failure. Failure is first initiated at the toe
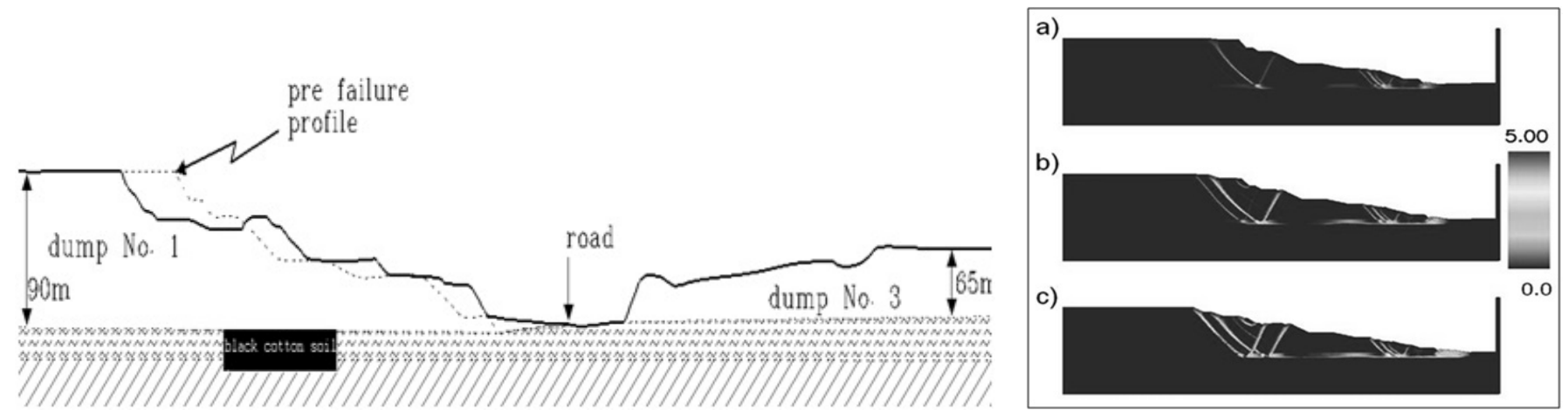

Fig. 11: (a) Overburden dumps in an Indian mine, the foundation consisted of 8-13 m soft soil. (b)t: CSIRO-SPH simulation of plastic strain in the slope of the overburden dump at three different times: a) after $12 \mathrm{~s}$, b) after $23 \mathrm{~s}$ and c) after 100 s. Source Lemiale and Karantgis (2014). 
of the dump, with an intense region of plastic strain developing in the black cotton soil foundation and propagating in the dump toward the lower bench surfaces (Fig. 11a and b). A set of two shear bands then rapidly propagates from the black cotton layer toward the upper surface of the dump, creating a failure wedge (Fig. 11a and b). The material located within this active wedge 'sinks' as deformation proceeds, while the material to the right of the wedge is displaced by translation, sliding along the slip surface created by the failure of the black cotton soil foundation (Fig. 11c). Secondary shear bands develop parallel to the first bands and cause the material to further fail along the slip planes (Fig. 11c).

In addition CSIRO has developed CSIRO-DEM (Cleary 2009; Cleary, 2010; Mead and Cleary 2011; Mead et al. 2012) and CSIRO-COSFLOW Adhikary and Dyskin 1997, Adhikary and Dyskin 1998, Adhikary et al., 1997, Adhikary and Guo 2002) methods for stress deformation analysis of structures on jointed rocks.

\section{CONCLUSIONS}

Our understanding of the failure mechanisms of large natural and engineered slopes has improved considerably over the past decade. Significant improvements have been made in innovative methods of data acquisition and numerical modelling techniques. CSIRO has developed novel techniques to facilitate efficient assessment of rock slope stability; these include:

- $\quad$ Sirovision ${ }^{T M}$ - for rock mass structural mapping,

- Siromodel - for discrete fracture network (DFN) generation, polyhedral (rock block) modelling and kinematic analysis,

- $\quad$ ERM modelling technique - for rock mass strength heterogeneity, anisotropy and scale dependency analysis, and

- CSIRO-SPH, CSIRO-DEM and CSIRO-COSFLOW codes - for large-scale rock mass stress deformation analysis.

The tools, techniques and approaches described in this paper can help remove many of the uncertainties and subjectiveness in landslide studies and assist in better landslide prediction and risk assessment consequently minimising costly damage to property and loss of life.

\section{REFERENCES}

Adhikary, D. P. and Dyskin, A. V., 1997, A Cosserat continuum model for layered media. Computers and Geotechnics, v. $20(1)$, pp. $15-45$.

Adhikary, D. P. and Dyskin, A. V., 1998, A continuum model of layered rock masses with non-associative joint plasticity. Int. Jour. Numer. Anal. Meth. Geomech., v. 22(4), pp. 245261.

Adhikary, D. P., Dyskin, A. V., and Jewell, R. J., 1996, Numerical modelling of the flexural deformation of foliated rock slopes. Int. Jour. Rock Mech. Min. Sci. and Mining Abstr., v. 33(6), pp. 595-606.

Adhikary, D. P., Dyskin, A. V., Jewell, R. J., and Stewart, D. P., A study of the mechanism of flexural toppling failure of rock slopes. Rock Mech. Rock Engg., v. 30(2), pp. 75-94.
Adhikary, D. P. and Guo, H., 2002, An orthotropic Cosserat elasto-plastic model for layered rocks. Rock Mech. Rock Engg., v. 35(3), pp. 161-170.

Beale, G. and Read, J., 2013, Guidelines for evaluating water in pit slope stability. CSIRO Publishing, 594p.

Bieniawski, Z. T., 1968, The effect of specimen size on compressive strength of coal. Int. Jour. Rock Mech. Min. Sci., v. 5, pp. 325-335.

Cleary, P. W., 2009, Industrial particle flow modelling using discrete element method. Eng. Computation., v. 26(6), pp. 698-743.

Cleary, P. W., 2010, DEM prediction of industrial and geophysical particle flows. Particuology, v. 8, pp. 106-118.

Cleary, P. W., 2010, Elastoplastic deformation during projectile-wall collision. Appl. Math. Model., v. 34(2), pp. 266-283.

Das, R. and Cleary, P. W., 2010, Effect of rock shapes on brittle fracture using Smoothed Particle Hydrodynamics. Theor. Appl. Fract. Mec., v. 53, pp. 47-60.

Elmouttie, M., Poropat, G., and Krahenbuhl, G., 2010, Polyhedral modelling of rock mass structure, Int. J. Rock Mech. \& Min. Sci., v. 47(4), pp. 544-552.

Hoek, E., 2007, Rock mass properties. Practical Rock Engineering, $47 \mathrm{p}$.

Iverson, R. M., Logan, M., and Denlinger, R. P., 2004, Granular avalanches across irregular three-dimensional terrain: 2 . Experimental tests. Jour. Geophys. Res., 109 p.

Lemiale, V. and Karantgis, L., 2014, SPH simulations of a mine overburden dumps failure as a case study. CSIRO Report No EP146367, 26 p.

Mead, S. and Cleary, P.W., 2011, Three dimensional avalanche modelling across irregular terrain using DEM: Comparison with experiment, In: Chan, F., Marinova, D. and Anderssen, R.S. (eds.) MODSIM2011, 19th International Congress on Modelling and Simulation, Modelling and Simulation Society of Australia and New Zealand, December 2011, pp. 2838-2844.

Mead, S., Delaney, G., and Lemiale, V. 2012, Discrete Element Method study of internal dump failure in Medapalli Opencast Mine: Model development and preliminary analysis, Report No. EP124926.

Menéndez-Díaz, A., González-Palacio, C., Álvarez-Vigil, A.E., González-Nicieza, C., and Ramírez-Oyanguren, P., 2009, Analysis of tetrahedral and pentahedral key blocks in underground excavations. Computers and Geotechnics, v. 36, pp. 1009-1023.

Nilsen B., 1979, Stabilitet av hoye fjrllskjaeringer. The Univ. of Trondheim, The Norwegian Institute of Technology, Reports from the Dept. of Geology, 280 p (in Norwegian).

Read, J. and Stacey, P., 2009, Guidelines for open pit slope design. CSIRO Publishing. 487 p.

Sidle, R. C. and Ziegler, A. D., 2012, The dilemma of mountain roads. Nature Geoscience, v. 5, pp. 437-438.

SirovisionTM User Manual, CAE Mining (2013).

Sjoberg, J., 1996, Analyses of large scale rock slopes. Doctoral Thesis, Lulea University of Technology, Sweden, $790 \mathrm{p}$.

Sjoberg, J., 1996, Large scale slope stability in open pit mining - a review, Technical report 1996:10T, Division of Rock Mech., Lulea University of Technology, Sweden. 229 p.

The Landslide Blog. The unusually large Bingham Canyon Mine landslide - an impressive example of prediction using monitoring, available at: <http://blogs.agu.org/ landslideblog/2013/04/12/the-unusually-large-bingham-can yon-mine-landslide-an-impressive-example-of-prediction-u sing-monitoring/>, accessed 15 March 2015. 